The International Journal of Engineering and Science (IJES)

|| Volume || 6 || Issue || 5 || Pages || PP 01-07 || 2017 ||

ISSN (e): $2319-1813 \operatorname{ISSN}$ (p): $2319-1805$

THE IJES

\title{
Triple Band Integrated Microstrip-Fed UWB Antenna for GSM, Radar and Satellite Communications
}

\author{
Dr.Seham Ahmed Hashem \\ Middle Technical University(MTU), Lecturer, Technical Electronic Department, Technical Instructors \\ Training institute, Baghdad, Iraq.
}

\begin{abstract}
A triple band integrated ultra-wideband $(U W B)$ antenna is proposed in this paper. This proposed antenna covers UWB frequency spectrum of $3.1-10.6 \mathrm{GHz}$ as well as other three frequencies bands namely $2 \mathrm{GHz}, 11$ $\mathrm{GHz}$ and $15 \mathrm{GHz}$ for GSM, radar and satellite communication applications respectively. The antenna consists of circular patch, substrate and ground structures. The circular patch is circularly etched on the top surface of substrate with appropriate dimension to achieve UWB spectrum. A thin strip is connected to the rectangular feed line with circular patch. The rectangular ground plane is designed on the back side of antenna with small slots. The proposed antenna is small in dimension and square type. The antenna is designed with the help of FR4 epoxy substrate with relative permittivity of 4.4. The dimension of proposed antenna is $30 \mathrm{~mm} \times 30 \mathrm{~mm} \times$ $1.6 \mathrm{~mm}$. A $50 \Omega$ microstrip feed line is used to feed the proposed antenna. The simulated results of the proposed antenna are under the standard parameters from $1.8 \mathrm{GHz}-16 \mathrm{GHz}$ frequency bandwidth having return loss < $10 \mathrm{~dB}$ and VSWR $\leq 2$. The return losses are $-26 \mathrm{~dB},-29 \mathrm{~dB}$ and $-17 \mathrm{~dB}$ at $2 \mathrm{GHz}, 11 \mathrm{GHz}$ and $15 \mathrm{GHz}$ respectively. Ansoft high frequency structure simulator (HFSS) tool is used for the designing and analysis of the proposed antenna.
\end{abstract}

Keywords: Ultra-wideband (UWB), GSM, Radar, Satellite, Patch, Substrate, Return loss, VSWR

Date of Submission: 29 April $2017 \quad$ Date of Accepted: 08 May 2017

\section{INTRODUCTION}

In modern communication system, the wireless technology becomes integral part of human life. Due to the advancement in technology, the requirement and usage of wireless communication applications are increase day by day. Due to the limited bandwidth, it is necessary to use an antenna for multiband functions [1]. An antenna is a key element to achieve multiband functins and it can be operate at more than one bands. The Federal Communications Commission (FCC) provides frequency spectrum in the range of $3.1-10.6 \mathrm{GHz}$ for ultrawideband (UWB) uses in 2002. Due to simple in design, economic in cost, low power requirement and provide excellent data rate, omnidirectional features, many researchers have found their research interest in design and analysis of UWB technology. For UWB communication systems, the FCC also provide an EIRP density of -41.3 $\mathrm{dBm} / \mathrm{MHz}$ [2-3]. Therefore it is necessary to design an antenna having multibands characteristics along with UWB frequency band. To design an UWB antenna integrated with other frequencies bands, L-shaped antenna[4] and fork-shaped antennas [5] are introduced to integrate UWB with Bluetooth bands. However, it is difficult to achieve three or more bands integrated with UWB range this is due to mutual coupling effect between elements. To overcome this challenge, several types of techniques are used using notched, adding strips with antenna. A multiband antenna is designed by using strips to the diamond shaped UWB antenna [6]. A triple band UWB result is obtained by using U-shaped strips with CPW structure [7]. Similarly there are also some UWB antennas that are designed for multibands operation using slots techniques [8-12]. By employing three folded capacitive loaded line resonator (CLLR) with the elliptical radiating patch, an UWB antenna integrated with other useful triple bands GSM/WCDMA/WLAN are achieved [13], by loading inverted L-strip over the patch antenna to achieved UWB microstrip antenna with triple bands [14].

In this research paper, a small size UWB antenna is designed and it also includes other three important frequency bands. Firstly covering the UWB band from $3.1-10.6 \mathrm{GHz}$, a circular radiating patch is used. The designed antenna is microstrip feed type due to microstrip atenna has lots of attractive features as low cost, compact, low power. On ther hand, by adding the a thin strip parallet to the ground just near the circular patch is responsible for one extra band. A rectangular ground plane is used on the back side of antenna and it has some rectangular slots at the middle part. From this arrangement, a triple band is achieved covering UWB frequency spectrum and also resonant at $2 \mathrm{GHz}, 11 \mathrm{GHz}$ and $15 \mathrm{GHz}$ frequencies for GSM, radar and satellite communicataion applications. 


\section{ANTENNA DESIGN}

In this design, we proposed an antenna which can be operate at multiband frequencies. Therefore it is necessary to design UWB antenna along with integration of triple frequencies bands. The structure consists of circular radiating patch, dielectric material called substrate and a ground plane as shown in fig1.

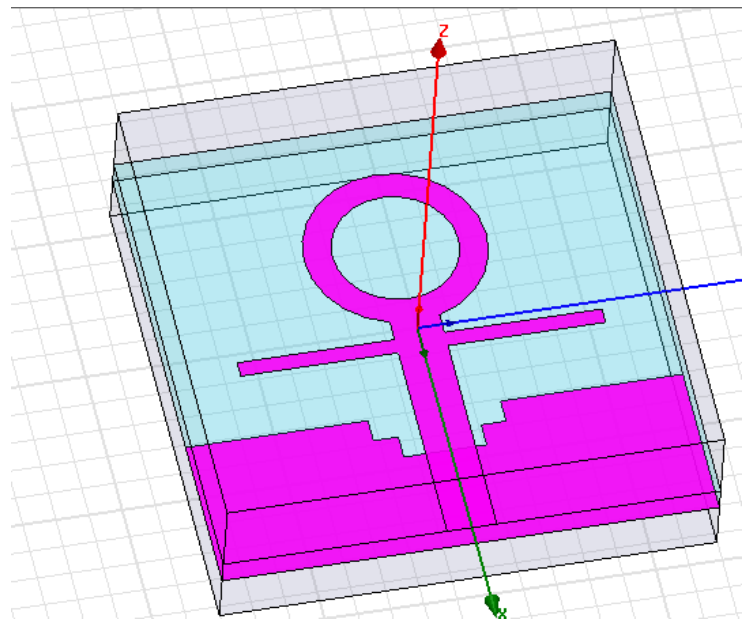

Fig.1. A general HFSS view of proposed antenna

Circular patch is etched with another small circle. The radia of two circles are $5.5 \mathrm{~mm}$ and $3.8 \mathrm{~mm}$ respectively. This circular patch is combine with a rectangular feed structure of size $16 \mathrm{~mm} \times 3 \mathrm{~mm}$. With the help of circularly etched design, UWB range ( $3.1-10.6 \mathrm{GHz}$ ) with one extra frequency band is achieved. The proposed microstrip antenna is implemented using FR4 epoxy dielectric with size of $30 \mathrm{~mm} \times 30 \mathrm{~mm} \times 1.6 \mathrm{~mm}$ and its permittivity is 4.4 . For adding one more band, a thin strip of size $1 \mathrm{~mm} \times 22 \mathrm{~mm}$ is connected to the circular radiating patch. To obtain the excellent excitation and good impedance matching charateristics of antenna, the length of strip is about quarter of wavelength and is given by

$\mathrm{L}=\lambda_{g} / 4$

Where $\lambda_{g}=\frac{c}{f \sqrt{\varepsilon_{\text {eff }}}}$ and $\varepsilon_{\text {eff }}=\left(\varepsilon_{r}+1\right) / 2$

In above equations, $\mathrm{L}$ is the length of strip, $\lambda_{\mathrm{g}}$ is wavelength, $\mathrm{c}$ is velocity of light and $\varepsilon$ is permittivity.

The ground structure is designed at the back side of antenna and is rectangular in size. The dimension of ground is $10 \mathrm{~mm} \times 30 \mathrm{~mm}$. In rectangular ground structure, small size rectangular slots are designed to obtain the remaining third resonant frequency band. The dimension of these small slots are mentioned by $\mathrm{a}, \mathrm{b}, \mathrm{c}$ and $\mathrm{d}$. Microstrip feedline of $50 \Omega$ is used for feeding.

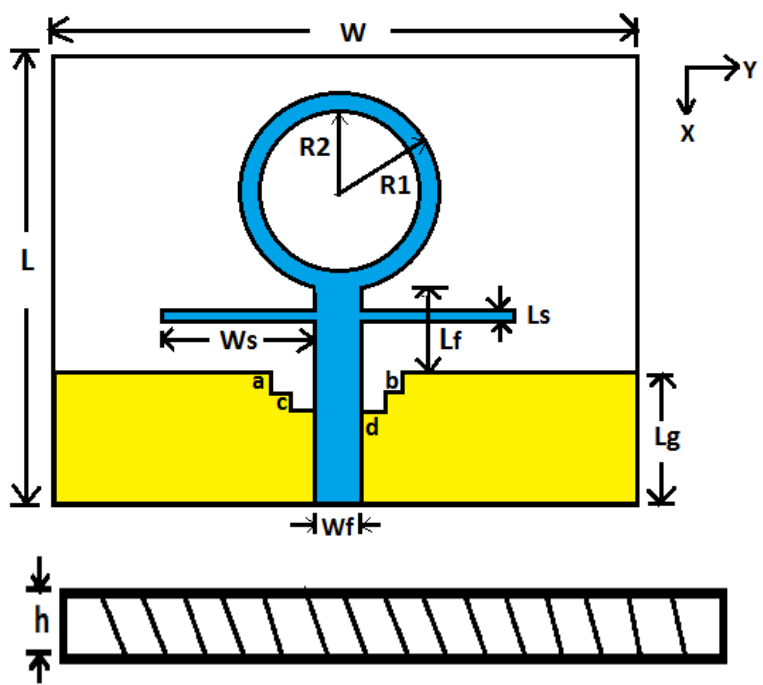

Fig.2. Schematic Geometry and dimensions 
The geometry and designing parameters of proposed antenna are shown in above fig 2 . In the second figure, it shows the height of the The antenna designing parameters and their dimensions are given in table 1.

Table1: Antenna design parameters and dimensions

\begin{tabular}{|l|l|l|l|}
\hline Parameters & Value $(\mathbf{m m})$ & Parameters & Value $(\mathbf{m m})$ \\
\hline L & 30 & R1 & 5.5 \\
\hline W & 30 & R2 & 3.8 \\
\hline Lg & 10 & a & 1.5 \\
\hline Wf & 3 & b & 1.5 \\
\hline Ls & 1 & c & 1.5 \\
\hline Ws & 9.5 & d & 1 \\
\hline Lf & 6 & h & 1.6 \\
\hline
\end{tabular}

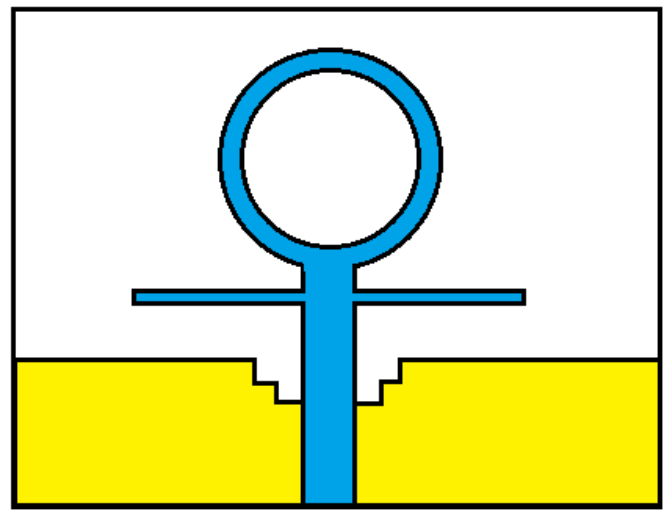

(a) General View

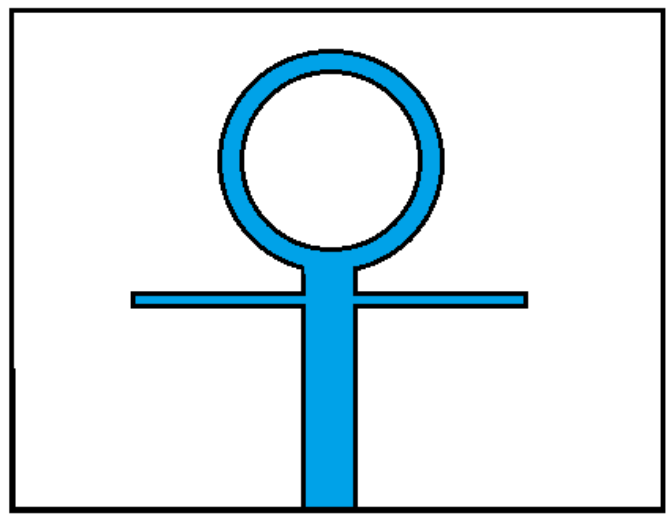

(b) Top View

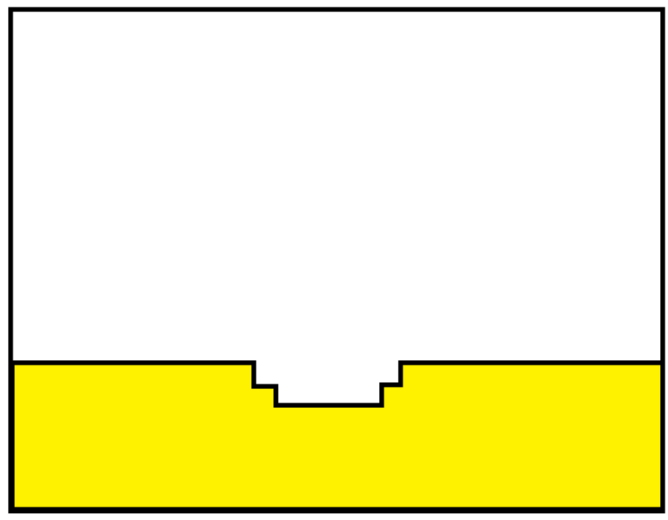

(c) Bottom View

Fig.3. Different views of proposed antenna antenna (a) General view (b) Top view (c) Bottom view 


\section{SIMULATION RESULT DISCUSSION AND ANALYSIS}

An Ansoft high frequecncy structure simulator (HFSS) software is used for the design and simulation of this proposed antenna [15]. From the simulation result, the obtained simulated parameters as return loss, VSWR, radiation pattern etc are good agreement with the ideal values. The simulated parameters of the proposed antenna are discussed below:

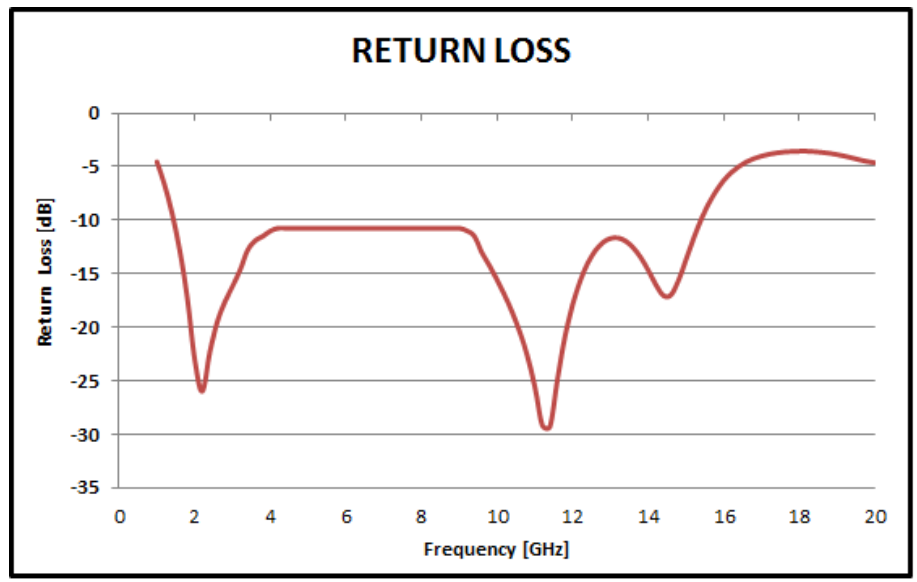

Fig.4. Return loss $\left(\mathrm{S}_{11}\right)$

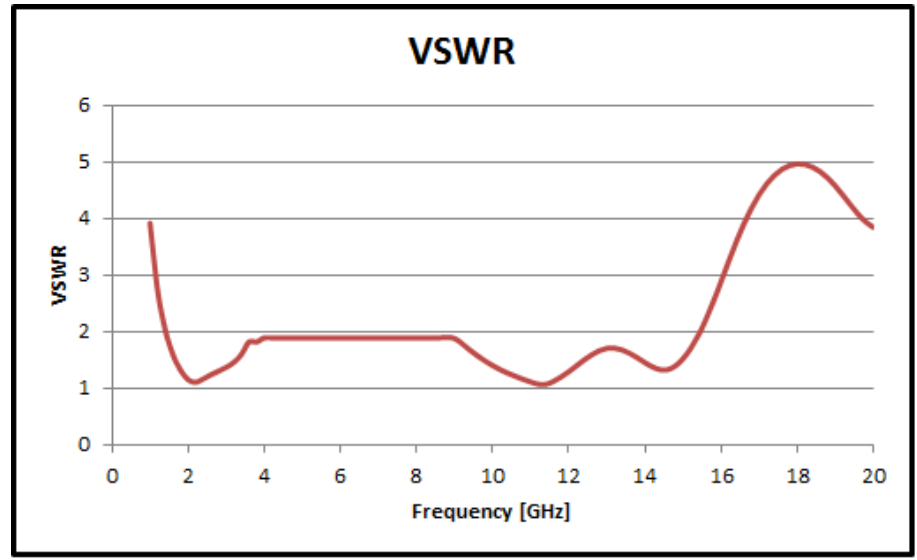

Fig.5. VSWR of proposed antenna

From fig 4. It clearly shows that the return loss $\left(\mathrm{S}_{11}\right)$ is $<-10 \mathrm{~dB}$. The designed and proposed antenna covers UWB and other three important bands. The antenna has good return loss in UWB frequency band and has - 26 $\mathrm{dB},-29 \mathrm{~dB}$ and $-17 \mathrm{~dB}$ of return losses at $2 \mathrm{GHz}, 11 \mathrm{GHz}$ and $15 \mathrm{GHz}$ frequency bands respectively. Similarly from fig 5, VSWR is alos $\leq 2$ throughout the $1.8 \mathrm{GHZ}$ to $16 \mathrm{GHz}$ frequency band and it also satisty the ideal conditions for both the UWB spectrum and other three integrated frequencies bands.

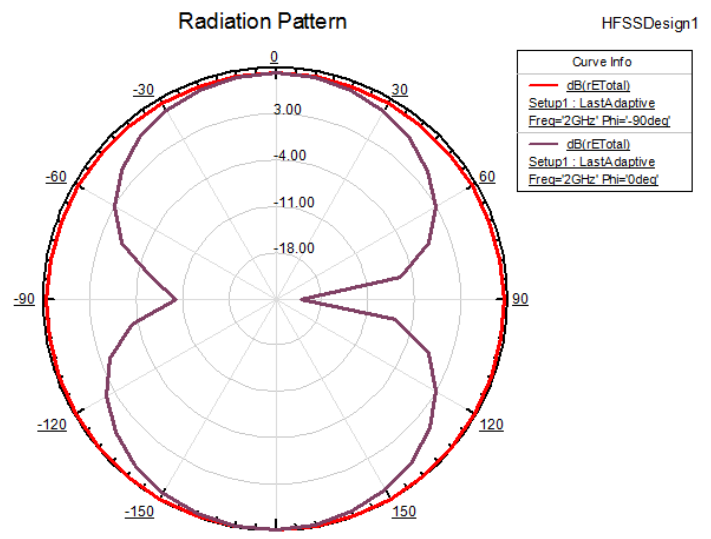

(a) Radiation pattern at $2 \mathrm{GHz}$ 


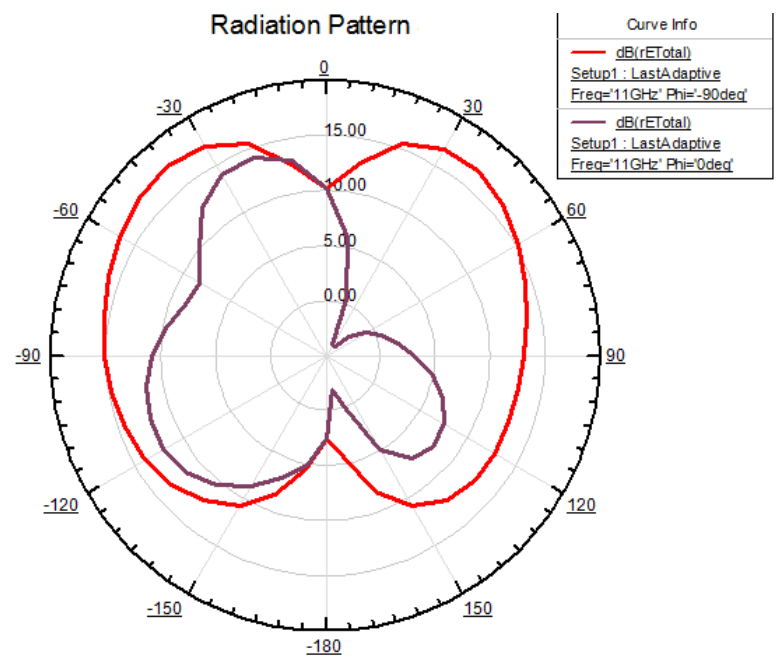

(b) Radiation pattern at $11 \mathrm{GHz}$

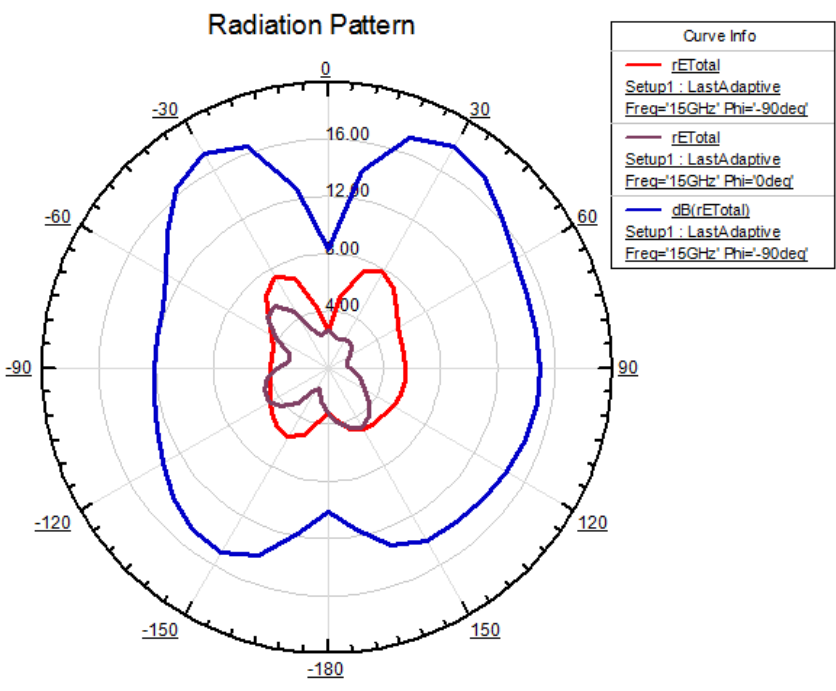

(c) Radiation pattern at $15 \mathrm{GHz}$

Fig.6. Field radiation patterns (a) at $2 \mathrm{GHz}$ (b) at $11 \mathrm{GHz}$ and (c) at $15 \mathrm{GHz}$

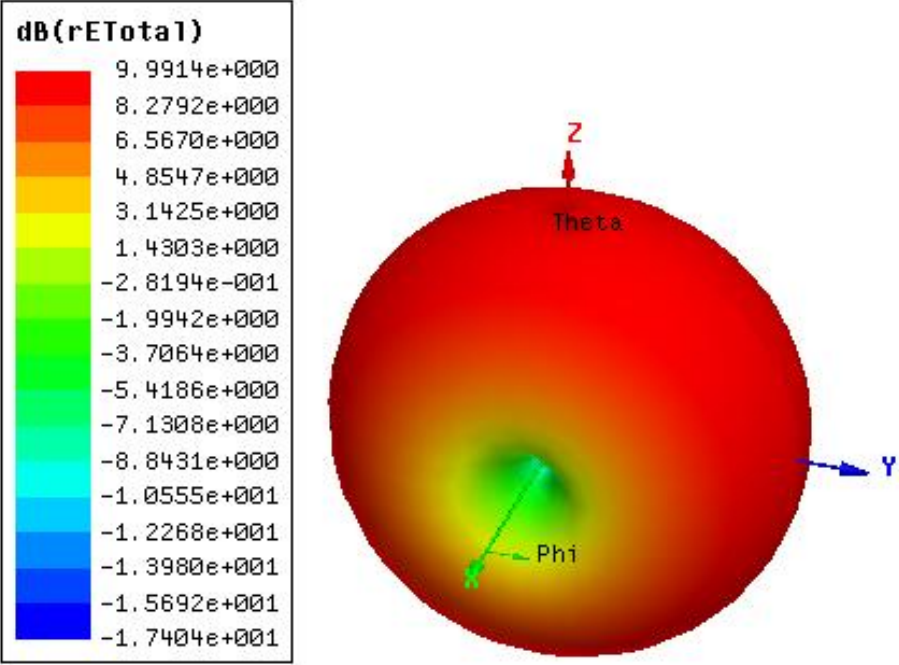

(a) Far Field pattern at 2 GHz 

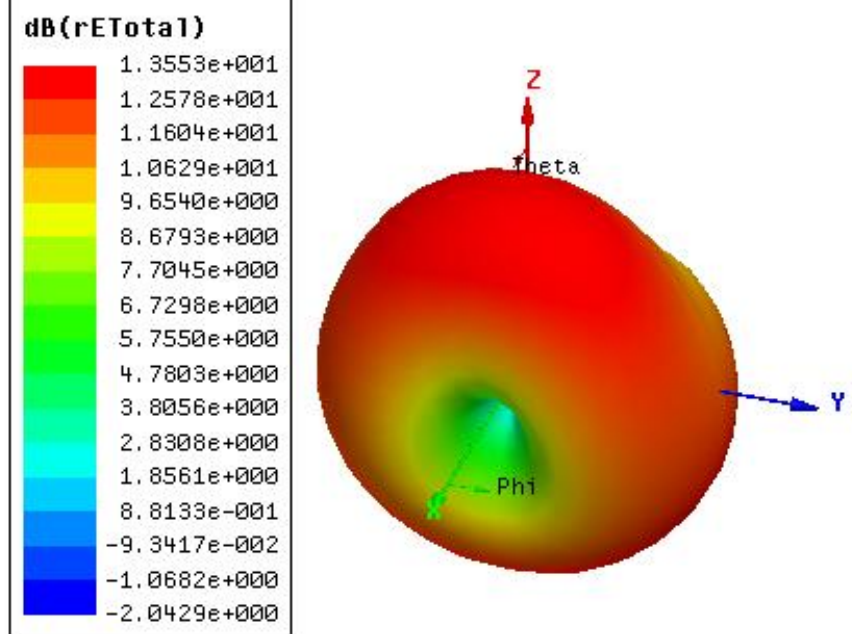

(b) Far Field pattern at $11 \mathrm{GHz}$

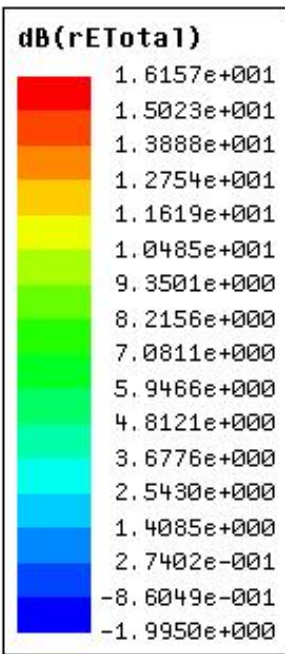

(c) Far Field pattern at $15 \mathrm{GHz}$

Fig.7 3-D Far-field patterns of the proposed antenna (a) at $2 \mathrm{GHz}$ (b) at $11 \mathrm{GHz}$ and (c) at $15 \mathrm{GHz}$

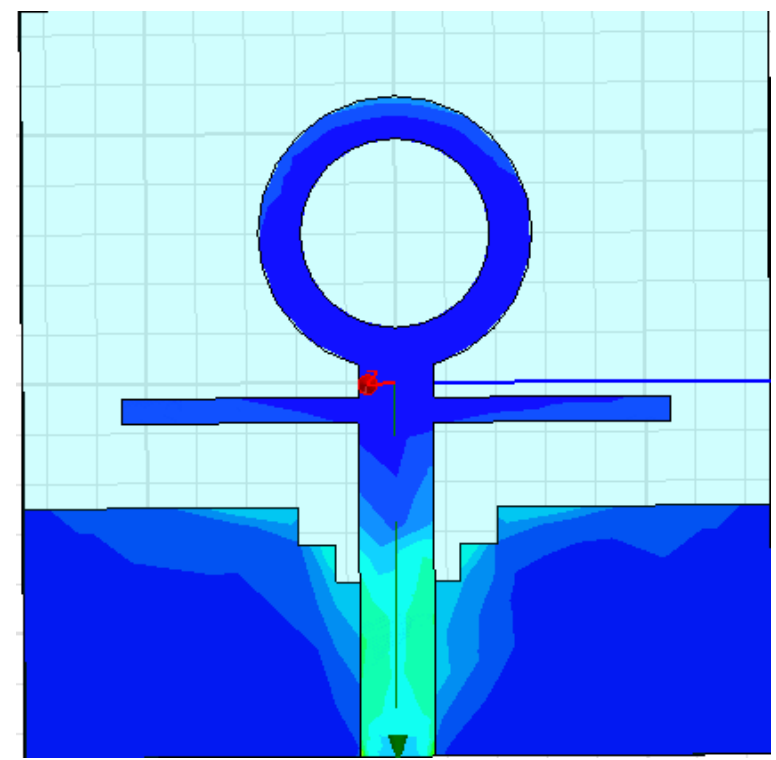

(a) $\mathbf{E}$-field 


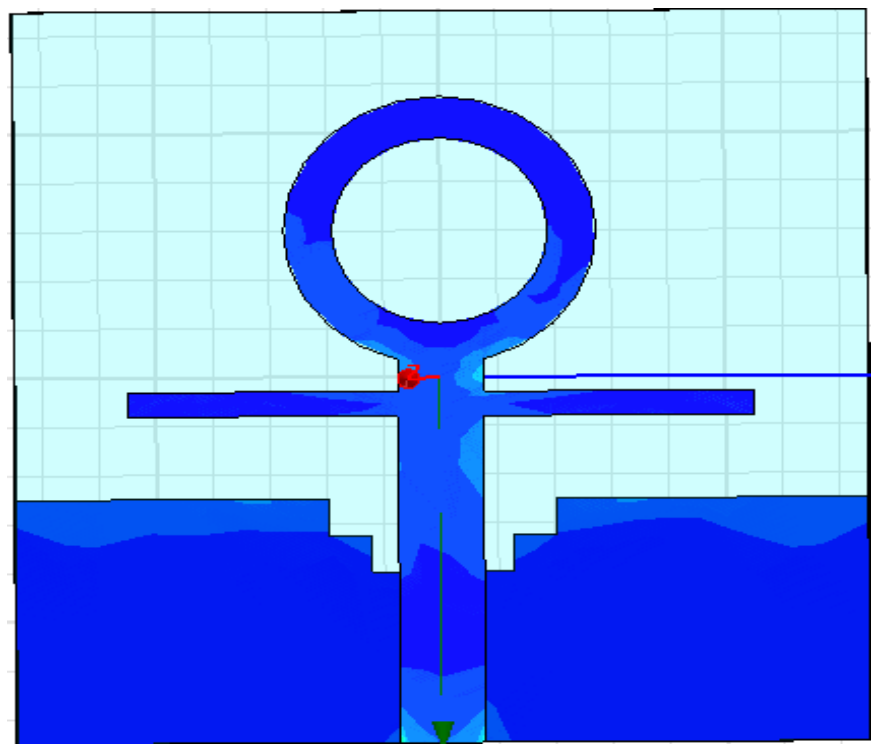

(b) $\mathbf{H}$-field

Fig.8. Field plot of the proposed antenna (a) E- field and (b) H-field

\section{CONCLUSION}

A novel and small size type of UWB antenna integrated with extra three bands has been designed and proposed. The proposed antenna has an excellent approach towards the broadband operation. The simulated result of proposed antenna cover frequency spectrum from $1.8 \mathrm{GHz}-16 \mathrm{GHz}$. This frequency band includes UWB frequency spectrum over $3.1-10.6 \mathrm{GHz}$ with integration of other important triple frequencies bands namely $2 \mathrm{GHz}, 11 \mathrm{GHz}$ and $15 \mathrm{GHz}$ for GSM, radar and satellite communication applications. The simulated results of proposed antenna such as return loss $(\mathrm{S} 11<-10 \mathrm{~dB})$, VSWR $(\leq 2)$ show the stable results over the entire UWB spectrum and other triple bands. The simulated return losses are $-26 \mathrm{~dB},-29 \mathrm{~dB}$ and $-17 \mathrm{~dB}$ at 2 $\mathrm{GHz}, 11 \mathrm{GHz}$ and $15 \mathrm{GHz}$ frequency bands respectively. The antenna shows omnidirectional radiation patter, stable antenna gain and high impedance matching property over the frequency band of $1.8-16 \mathrm{GHz}$ ( 14.2 $\mathrm{GHz}$ ). Due to compact size and excellent results, this proposed antenna is a appropriate for UWB applications and other three frequencies bands also.

\section{REFERENCES}

[1]. Zhao, Q., S.-X. Gong, W. Jiang, B. Yang, and J. Xie, "Compactwide-slot tri-band antenna for WLAN/WiMAX applications," Progress In Electromagnetics Research Letters, Vol. 18, 9-18, 2010.

[2]. First report and order,(2002) “Revision of Part 15 of the commission's rule regarding ultrawideband transmission system FCC02-48", Federal Communications Commission.

[3]. Mishra, S. K., R. K. Gupta, A. Vaidya, and J. Mukherjee, "Printed Fork Shaped Dual Band Monopole Antenna For Bluetooth And UWB Applications With 5.5GHz WLAN Band Notchedchar-Acteristics," Progress In Electromagnetics Research C, Vol. 22, 195$210,2011$.

[4]. Yildirim, B. S., B. A. Cetiner, G. Roquetra, and L. Jofre,’Integrated bluetooth and UWB antenna," IEEE Antennas Wireless Propag. Lett., Vol. 8, 149-152, 2009.

[5]. Mishra, S. K., R. K. Gupta, A. Vaidya, and J. Mukherjee, “A compact dual-band fork-shaped monopole antenna for Bluetooth and UWB applications," IEEE Antennas Wireless Propag. Lett., Vol. 10, 627-630,2011.

[6]. Foudazi, A., H. R. Hassani, and S. M. Ali Nezhad, "Small UWB planar monopole antenna with added GPS/GSM/WLAN bands,"IEEE Trans. Antennas Propag., Vol. 60, No. 6, 2987-2992, 2012.

[7]. Bod, M., H. R. Hassani, and M. M. Samadi Taheri, "Compact UWB printed slot antenna with extra bluetooth, GSM, and GPS bands," IEEE Antennas Wireless Propag. Lett., Vol. 11, 531-534, 2012.

[8]. Huda A. Majid, Mohamad K. A. Rahim, Mohamad R. Hamid, and Muhammad F. Ismail, Frequency Reconfigurable Microstrip Patch-Slot Antenna with Directional Radiation Pattern, Progress In Electromagnetics Research, Vol. 144,pp. 319-328, 2014.

[9]. Y. Sung, A Printed Wide-Slot Antenna With a Modified L-Shaped Microstrip Line for Wideband Applications, IEEE Transactions On Antennas And Propagation, Vol. 59, pp. 10, October 2011.

[10]. Mohammad Reza Ghaderi, and Farzad Mohajeri, A Compact Hexagonal Wide-Slot Antenna With Microstrip-Fed Monopole for UWB Application, IEEE Antennas And Wireless Propagation Letters, Vol. 10, 2011.

[11]. Kun Song, Ying-zeng Yin, Huan-huan Xie, Shao-li Zuo, and Dan Xi, A corner-truncated patch scheme of bandwidth enhancement for open slot antenna, Proceedings of International Symposium on Signals, Systems and Electronics (ISSSE) 2010.

[12]. Y. Sung, Bandwidth Enhancement of a Microstrip Line-Fed Printed Wide-Slot Antenna With a Parasitic Center Patch, IEEE Transactions On Antennas And Propagation, Vol. 60, pp. 4, April 2012.

[13]. Guihong Li*, Huiqing Zhai, Tong Li, Xiaoyan Ma, and Changhong Liang, "Design of a compact UWB antenna integrated with GSM/WCDMA/WLAN bands, ” Progress In Electromagnetics Research, Vol. 136, 409-419,2013.

[14]. Anil Kr Gautam, Swati Yadav and Binod Kr Kanaujia, "A CPW-Fed Compact UWB Microstrip Antenna”, IEEE Antennas And Wireless Propagation Letters, Vol. 12, 2013

[15]. Ansoft Corporation - HFSS - www.ansoft.com 